\title{
Academic anxiety among urban adolescents: A study of gender differences
}

\section{ASHA CHAWLA AND DEEPIKA VIG}

Received: 01.03.2014; Accepted: 09.11.2014

See end of the paper for authors' affiliations ASHA CHAWLA

Department of Human Development, College of Home Science, Punjab Agricultural University, LUDHIANA (PUNJAB) INDIA
ABSTRACT : Present study was an attempt to investigate the gender differences in academic anxiety of urban adolescents. Gender differences in academic anxiety have been highlighted by many researchers. The total sample for the present study consisted of 100 urban adolescents studying in $10^{\text {th }}$ standard in various public schools of Ludhiana city. The study was evenly distributed over two sexes i.e. 50 boys and 50 girls. The result of the present study revealed that 42 per cent of the boys and 74 per cent of the girls were found to have medium level of anxiety. Further, it was found that urban girls showed significantly more academic anxiety than urban boys. The result emphasises the need to teach simple strategies to adolescent girls for managing their anxiety effectively. Parent education programme can also be initiated so that parents can guide and provide practical support to girls on issues related to academic performance.

KEY WORDS: Academic anxiety, Gender difference, Adolescents

- HOW TO CITE THIS PAPER : Chawla, Asha and Vig, Deepika (2014). Academic anxiety among urban adolescents: A study of gender differences. Asian J. Home Sci., 9 (2) : 598-600. 